\title{
Occlusal overload with dental implants: a review
}

\author{
Steven J. Sadowsky
}

\begin{abstract}
Controversy persists as to the role of occlusal overload in peri-implantitis. Animal studies have not revealed the biological threshold for fatigue failure in the peri-implant bone. On the other hand, clinical studies have demonstrated a link between parafunction and implant failure, although variables such as intensity and frequency of loads, as well as bone density, have led to different outcomes. The absence of specific engineering "building codes" for the clinician has relegated prosthetic design planning to intuitive guidelines for all patients. For example, higher crown to implant ratios (2-3:1), implant cantilever prostheses and non-splinted restorative designs have been avoided because of the concern for overload. However, evidence has not supported this general approach. A call for preclinical research to establish specific patient load thresholds is in order to establish a customized treatment plan.
\end{abstract}

\section{Introduction}

According to the American Academy of Implant Dentistry, 500,000 dental implants are placed in the USA annually. These numbers continue to climb despite the unknown role of occlusion in the biological outcomes of osseointegrated implants [1]. Natural teeth that present with initial occlusal discrepancies have demonstrated deeper probing depths and poorer prognoses than those without these discrepancies [2]. However, there are no controlled studies that evaluate the effect of occlusion on implants in humans, due to the fact that they would be countered to the Helsinki accords [3]. What remains is an available body of evidence that is broad and heterogeneous. What is lacking is a study that would reveal the link between specific mechanical loads and histological changes, to serve as a guide to the clinician for implant prosthetic design and occlusal therapy. It is known that the response to increased mechanical stress below a certain threshold will strengthen the bone by increasing the bone density or apposition of the bone $[4,5]$. On the other hand, fatigue microdamage resulting in resorption of the bone may be the product of mechanical stress above this threshold [6]. If this gradient could be defined for implant restorations, it would clarify a topic in implant dentistry that has been fueled more by dogma, expert opinion, and inferences

Correspondence: ssadowssky@pacific.edu

Preventive and Restorative Department, University of Pacific Arthur A.

Dugoni School of Dentistry, San Francisco, California, USA from concepts used for natural teeth [7]. The purpose of this study is to review the current preclinical and clinical literature on occlusal overload and its relationship to peri-implant bone loss as well as establish the need for future research.

\section{Animal studies}

Isidor [8-10] published a series of experimental studies using four monkeys to compare the loss of the bone around dental implants following an excessive load or plaque accumulation. He used both machined and titanium dioxide-surfaced implants. After 18 months of loading, the histological result showed that 6 out of 8 loaded implants lost osseointegration. It was concluded that occlusal overload can be the main factor for bone loss for an implant already osseointegrated. In agreement, Miyata et al. [11] experimented with different heights of the superstructure $(100,180,250 \mu \mathrm{m})$ using the same breed of monkeys and found increased bone resorption occurred with an excess of $180 \mu \mathrm{m}$ or higher after 4 weeks of loading.

However, Heitz-Mayfield et al. [12] using Labrador dogs found no marginal bone loss due to excessive occlusal forces. This study included six dogs and each dog's bilateral mandibular premolar and molar was removed. After 3 months of healing, two titanium plasma sprayed and two sandblast, large grit acid-etched implants were placed in each side of the mandible in all dogs. A split-mouth design was conducted with supraoccluding crowns on the one side and on the other side 
unloaded. Plaque control was performed on all implants throughout the experimental time. After 8 months of loading, histology revealed that mineralized bone in contact with the control and test surfaces was not statistically disparate, $72.6 \%$ and $73.9 \%$, respectively.

Similar findings were reported by Kozlovsky et al. [13], who performed a split-mouth design on Beagle dogs, placing prosthetic abutments on implants, either in supraocclusion or infraocclusion. They found no loss of osseointegration or marginal bone loss with non-inflamed, occlusally overloaded prostheses on dental implants. In fact, the authors demonstrated, in the absence of inflammation, there was an increase in the bone to implant contact when overloading the implants.

As is apparent, there are conflicting data in these experimental studies which can be attributed to confounding variables such as differences in experimental design, occlusal overload, and bone quality. Lateral forces applied on the implant prostheses in dogs could only be simulated by artificially created cusp inclines of different types as dogs are unable to perform lateral movements. Some researchers created a lateral displacement on the supra-occluding cusp where others created premature contact in centric occlusion. Finally, different regimens of oral hygiene were used and certainly could not preclude the presence of peri-implant inflammation.

Despite the conflicting evidence, two conclusions have been drawn [7]. Precipitous bone loss from overloading has been shown in a few investigations, but the majority of the more recent animal studies has not replicated these findings. Total loss of osseointegration of an integrated implant appears possible when the applied force exceeds the biological threshold, but this limit is currently unknown, and contingent on the bone quality and possibly the level of inflammation. While it is difficult to quantify the magnitude and direction of naturally occurring occlusal forces, a number of clinical studies may offer clues to appropriate implant/prosthetic treatment planning to minimize peri-implant disease and point to future research.

\section{Clinical studies}

\section{Bruxism}

Twenty percent to $35.9 \%$ of patients may generate forces of such magnitude to cause microfracture of the bone around dental implants with concomitant bone loss and implant failure due to bruxism [14-18]. Of note, statistical mediating factors are implant length, diameter, and surface as well as bone quantity D vs. A (Bone quantity relates to the bone volume present. Division A is the height of the bone more than $10 \mathrm{~mm}$. Division $\mathrm{B}$ is more than $10 \mathrm{~mm}$ in height, but the width at the crest is $2.5-5 \mathrm{~mm}$. Division $\mathrm{C}$ is less than $10 \mathrm{~mm}$ in height and width atrophied to less than $2.5 \mathrm{~mm}$. Division D is severely deficient bone. Both Division C and D will require augmentation procedures) and bone quality 4 in relation to 1 (Bone quality relates to density present. Type 1 dense bone provides great cortical anchorage but limited vascularity. Type 2 bone is the best bone for osseointegration. Type 3 and 4 bone have soft bone textures with the least success of implant integration in type 4 bone) using Lekholm and Zarb classification [15]. However, given a population of 98 bruxers and matched non-bruxers, considering these variables, the odds ratio of implant failure has been shown to be 2.71 in relation to non-bruxers [16]. Furthermore, Chitumalla et al. [19] in a recent 5-year retrospective study reported a survival rate of dental implants with bruxism habit was $90 \%$ after 1 year, $87 \%$ after 2 years, $85 \%$ after 3 years, $75 \%$ after 4 years, and $72 \%$ after 5 years. Other investigators have corroborated the link between parafunction and implant failure [20, 21]. This underscores the link between occlusal overload and peri-implant disease and ultimately failure. It is likely that forces applied to implants during bruxism are even higher than those exerted onto natural teeth due to the decreased proprioception of implants. The periodontal ligament of natural teeth provides the central nerve system with feedback for sensory and motor control vs. the implant having feedback from only distant mechanoreceptors and therefore lowers tactile sensitivity (8-fold!) [22]. Another reason is that without a periodontal ligament, implant occlusal loads are directly transferred to the bone leading to higher forces to the supporting structure surrounding implants and risk for bony microfracture (peri-implantitis), compared to natural teeth.

In order to measure bite forces, the most widely accepted recording device is the strain gauge bite force transducer [23-28]. Mean bite force measurements in bruxers have been shown to be $827 \mathrm{~N}$ with a standard deviation of $620 \mathrm{~N}$ [29]. Bruxers generate both an increased magnitude of force and a higher frequency of tooth contact than non-bruxers [30]. Nishigawa et al. [31] found that $790 \mathrm{~N}$ of force was on average generated during bruxism and a mean duration of $7.1 \mathrm{~s}$. Normal masticatory loads have been described as being brief in nature $(0.23$ to 0.3 contacts/s) at 1 to $2 \mathrm{~Hz}$ for a total period of approximately 9 to $17 \mathrm{~min}$ per day [32]. Pathologic overloading may also occur as a result of duration of contact. This can magnify loads and stress leading to strain gradients exceeding the physiologic tolerance threshold of the bone, causing microfractures at the bone-implant interface. While repeated single high loads can lead to failure and cause microfractures within the bone tissue, continuous application of low loads may also lead to fatigue failure [33]. The mineralized bone matrix has a mechanical and biologic "memory" for previous stimuli [34]. 
A microstrain level that is over 4000 is commonly indexed as the threshold for bone fatigue failure [35]. This ceiling varies in accordance with high or low cancellous bone density models with former achieving higher maximums. A high-density cancellous bone (850 Hounsfield units) and a low-density cancellous bone (150 Hounsfield units) would be categorized as type 1 and 4 quality bone, respectively [36, 37]. At the same time, intermittent bouts of 1000 to 3000 microstrains have shown to have a stimulating, anabolic effect on bone mass [38]. This has been explained by Frost [39]. He has identified osteocytes as an important part of the cellular machinery of bone functional adaptation. When the strain stimulus surpasses the homeostatic regulatory mechanism threshold, but is below the bone fatigue failure, tissue level strains lead to fluid flow-mediated osteocyte and dendrite perturbation and release of anabolic factors. In turn, osteoblasts are recruited and the bone is subsequently formed primarily on trabecular and periosteal surfaces-effectively increasing whole bone strength [40].

\section{Crown to implant ratio}

An example of this phenomenon is demonstrated with implants that have a crown to implant ratios of greater than 1 to 1 . A number of investigators reported counterintuitive results when high clinical crown to implant ratios (2-3 C/I ratio) did not have the expected catabolic result, but instead caused an anabolic change in the bone [41-44]. The use of short implants when there is a significant interocclusal distance has similarly been successful, even when compared to longer implants with bone augmentation [45-47]. It also offers a methodological pathway to look at relative force/field units in the anabolic/catabolic bone continuum and its tipping point for peri-implantitis.

\section{Implant cantilever prostheses}

Another implant prosthetic design that has been assumed to cause occlusal overload is the cantilever prosthesis. However, systematic reviews and meta-analyses as well as long-term follow-up studies of cantilevers in the partially edentulous patients have demonstrated similar marginal bone levels as the fixed dental prostheses without a cantilever [48-53]. This is irrespective of the use of a mesial or distal cantilever [54]. However, there are limits dictated by the design of the cantilever.

Non-axial forces on natural teeth are mediated through the tensile loading of the principal fibers of the periodontal ligament (PDL), and the occlusal load is transmitted to the surrounding bone [55]. Non-axial loads as in balancing interferences on the teeth have been associated with the significant interproximal bone loss [31]. With implants, the load is transferred directly from the implant to surrounding bone through the ankylosed root analog and adverse effects have not been found to be as pronounced during non-axial loading [56]. However, there are thresholds of non-axial forces that have been shown to cause crestal bone loss around implants. Duyck et al. [57] have shown that a transverse force of $14.7 \mathrm{~N}$ applied on a distance of $50 \mathrm{~mm}$ from the top of the implant results in a bending moment of $73.5 \mathrm{Ncm}$ when repeated with 2520 cycles at a frequency of $1 \mathrm{~Hz}$ causes crater like defects lateral to the osseointegrated implants. This may offer a threshold to explain why fixed dental prostheses that are designed with cantilever arms $\geq 8 \mathrm{~mm}$ have demonstrated marginal bone loss, leading to peri-implantitis [58].

\section{Splinting}

The use of splinting to decrease force magnitudes on implant restorations and thereby protect against occlusal overload leading to marginal bone loss continues to be controversial. Vigolo et al. [59] conducted a 10-year splitmouth design on 44 patients with splinted and nonsplinted implant restorations on the right and left maxillary posterior quadrant, respectively. He found no difference in crestal bone loss, despite that $17 \%$ of the implants were placed in bone quality type IV. However, notable to the patient cohort profile was the absence of any bruxers. Naert et al. [60] treated a larger population with 644 implants. Two hundred thirty-five were restored with single crowns and 409 with a splinted prosthesis. After a 16-year follow-up, $95.8 \%$ of all restorations survived. Statistical analysis showed no significant difference in hazard rate between implant-supported single crowns and those splinted by means of fixed prostheses. It was also shown that neither restoration design, jaw site nor implant position (anterior or posterior) had a significant effect on bone loss [61]. Despite the fact that patients were widely accepted for treatment, no data were reported on the number of bruxers. While recommendations have been made to splint crowns in patients with parafunction [62, 63], no clinical or histological evidence has demonstrated marginal bone response advantages.

\section{Discussion}

Treatment planning implant-prosthetic rehabilitation should be dependent on a biomechanical algorithm customized for each patient. Given the lack of a definitive load-bearing analysis for bone supporting implants, an empirical or intuitive dogma, based on a tooth model, has proliferated in the clinical amphitheater. This has led to a penchant for invasive and costly procedures rather than more minimally invasive approaches. While short implants (even with high crown to implant ratios) can successfully override augmentation procedures, and implant cantilevers can dependably reduce surgical exposure as well 
as soft tissue problems, and splinting may not be necessary to maintain the marginal bone level; biases against short implants, implant cantilevers, and non-splinted units are replete and are not evidence-based. Despite this so-called safe approach to implant treatment planning, peri-implantitis is on the rise. Understanding the role that mechanical stress and strain play in periimplant bone loss may change the tooth model as a guide for implant prosthetic designs and assist in explaining why peri-implantitis has been so prevalent.

This study is limited by the non-systematic nature of its review. However, there are no randomized or prospective human trials on occlusal overload due to the ethical concerns in such methodologies. The way forward will be in designing and conducting overload conditions in preclinical experiments and using finite element analyses to identify thresholds of bone microstrain for assessing safe implant/prosthetic designs for our patients.

\section{Summary}

When the best available evidence is lacking in directing clinicians in their treatment planning decisions with implant restorations, a basic science approach can offer clarity. The relationship between mechanical loading and biologic consequences on bone response has been established, but specific thresholds have not been correlated to prosthetic design and occlusal scheme guidelines. The high ceiling of implant survival has clouded the importance of dissecting why some implants fail. It has been sobering, however, to note that as high as $20 \%$ of all implant patients experience peri-implantitis, while the impact of occlusal overload remains unknown.

\section{Acknowledgements \\ None}

\section{Author's contributions}

The author read and approved the final manuscript.

\section{Funding}

N/A.

\section{Availability of data and materials \\ N/A.}

Ethics approval and consent to participate

N/A

\section{Consent for publication}

N/A.

\section{Competing interests}

Steven J. Sadowsky declares that he has no competing interests.

Received: 28 March 2019 Accepted: 17 June 2019

Published online: 23 July 2019

\section{References}

1. Taylor TD, Wiens J, Carr A. Evidence-based considerations for removable prosthodontic and dental implant occlusion: a literature review. J Prosthet Dent. 2005;94(6):555-60.
2. Nunn ME, Harrel SK. The effect of occlusal discrepancies on periodontitis. I. Relationship of initial occlusal discrepancies to initial clinical parameters. J Periodontol. 2001;72(4):485-94.

3. Graves CV, Harrel SK, Rossmann JA, et al. The role of occlusion in the dental implant and peri-implant condition: a review. Open Dent J. 2016;10:594-601.

4. Frost HM. A 2003 update of bone physiology and Wolff's law for clinicians. Angle Orthod. 2004;74(1):3-15.

5. Frost HM. Wolff's law and bone's structural adaptations to mechanical usage: an overview for clinicians. Angle Orthod. 1994;64(3):175-88.

6. Isidor F. Influence of forces on peri-implant bone. Clin Oral Implants Res. 2006;17(Suppl 2):8-18.

7. Chang M, Chronopoulos V, Mattheos N. Impact of excessive occlusal load on successfully-osseointegrated dental implants: a literature review. J Investig Clin Dent. 2013:4(3):142-50.

8. Isidor F. Loss of osseointegration caused by occlusal load of oral implants. A clinical and radiographic study in monkeys. Clin Oral Implants Res. 1996;7(2):143-52.

9. Isidor F. Histological evaluation of peri-implant bone at implants subjected to occlusal overload or plaque accumulation. Clin Oral Implants Res. 1997;8(1):1-9.

10. Isidor F. Clinical probing and radiographic assessment in relation to the histologic bone level at oral implants in monkeys. Clin Oral Implants Res. 1997:8(4):255-64.

11. Miyata T, Kobayashi Y, Araki H, Ohto T, Shin K. The influence of controlled occlusal overload on peri-implant tissue. Part 3: a histologic study in monkeys. Int J Oral Maxillofac Implants. 2000;15(3):425-31.

12. Heitz-Mayfield LJ, Schmid B, Weigel C, et al. Does excessive occlusal load affect osseointegration? An experimental study in the dog. Clin Oral Implants Res. 2004;15(3):259-68.

13. Kozlovsky A, Tal H, Laufer BZ, et al. Impact of implant overloading on the peri-implant bone in inflamed and non-inflamed peri-implant mucosa. Clin Oral Implants Res. 2007;18(5):601-10.

14. Glaros AG. Incidence of diurnal and nocturnal bruxism. J Prosthet Dent. 1981;45(5):545-9.

15. Chrcanovic BR, Kisch J, Albrektsson T, Wennerberg A. Bruxism and dental implant failures: a multilevel mixed effects parametric survival analysis approach. J Oral Rehabil. 2016;43(11):813-23.

16. Chrcanovic BR, Kisch J, Albrektsson T, Wennerberg A. Bruxism and dental implant treatment complications: a retrospective comparative study of 98 bruxer patients and a matched group. Clin Oral Implants Res. 2017;28(7):e1-9.

17. Capurso U. Clinical aspects of craniomandibular disorders. I. Analysis of a sample group of patients and diagnostic classification. Minerva Stomatol. 1996;45(7-8):311-20.

18. Lavigne GJ, Khoury S, Abe S, Yamaguchi T, Raphael K. Bruxism physiology and pathology: an overview for clinicians. J Oral Rehabil. 2008:35(7):476-94.

19. Chitumalla R, Halini Kumari KV, Mohapatra A, et al. Assessment of survival rate of dental implants in patients with bruxism: a 5-year retrospective study. Contemp Clin Dent. 2018;9(Suppl 2):S278-s82.

20. Glauser R, Ree A, Lundgren A, et al. Immediate occlusal loading of Branemark implants applied in various jawbone regions: a prospective, 1year clinical study. Clin Implant Dent Relat Res. 2001;3(4):204-13.

21. Misch CE. The effect of bruxism on treatment planning for dental implants. Dent Today. 2002;21(9):76-81.

22. Hammerle $\mathrm{CH}$, Wagner $\mathrm{D}$, Bragger $\mathrm{U}$, et al. Threshold of tactile sensitivity perceived with dental endosseous implants and natural teeth. Clin Oral Implants Res. 1995;6(2):83-90.

23. Baba K, Clark GT, Watanabe T, Ohyama T. Bruxism force detection by a piezoelectric film-based recording device in sleeping humans. J Orofac Pain. 2003;17(1):58-64.

24. Paphangkorakit J, Osborn JW. Effect of jaw opening on the direction and magnitude of human incisal bite forces. J Dent Res. 1997;76(1):561-7.

25. Nishigawa K, Bando E, Nakano M. Quantitative study of bite force during sleep associated bruxism. J Oral Rehabil. 2001;28(5):485-91.

26. Schindler HJ, Turp JC, Blaser R, Lenz J. Differential activity patterns in the masseter muscle under simulated clenching and grinding forces. J Oral Rehabil. 2005:32(8):552-63.

27. Tortopidis D, Lyons MF, Baxendale RH. Bite force, endurance and masseter muscle fatigue in healthy edentulous subjects and those with TMD. J Oral Rehabil. 1999;26(4):321-8. 
28. Kikuchi M, Korioth TW, Hannam AG. The association among occlusal contacts, clenching effort, and bite force distribution in man. J Dent Res. 1997;76(6):1316-25.

29. Alkan A, Bulut E, Arici S, Sato S. Evaluation of treatments in patients with nocturnal bruxism on bite force and occlusal contact area: a preliminary report. Eur J Dent. 2008;2(4):276-82

30. Camparis CM, Formigoni G, Teixeira MJ, et al. Sleep bruxism and temporomandibular disorder: clinical and polysomnographic evaluation. Arch Oral Biol. 2006;51(9):721-8.

31. Yuodelis RA, Mann WV Jr. The prevalence and possible role of nonworking contacts in periodontal disease. Periodontics. 1965;3(5):219-23.

32. Graf H. Bruxism. Dent Clin N Am. 1969;13(3):659-65.

33. Sohn BS, Heo SJ, Koak JY, Kim SK, Lee SY. Strain of implants depending on occlusion types in mandibular implant-supported fixed prostheses. J Adv Prosthodont. 2011;3(1):1-9.

34. Brand RA, Stanford CM. How connective tissues temporally process mechanical stimuli. Med Hypotheses. 1994:42(2):99-104.

35. Sugiura T, Yamamoto K, Kawakami M, et al. Influence of bone parameters on peri-implant bone strain distribution in the posterior mandible. Med Oral Patol Oral Cir Bucal. 2015;20(1):e66-73.

36. de Oliveira RC, Leles CR, Normanha LM, Lindh C, Ribeiro-Rotta RF. Assessments of trabecular bone density at implant sites on CT images. Oral Surg Oral Med Oral Pathol Oral Radiol Endod. 2008;105(2):231-8.

37. Norton MR, Gamble C. Bone classification: an objective scale of bone density using the computerized tomography scan. Clin Oral Implants Res. 2001;12(1):79-84.

38. Reijnders CM, Bravenboer N, Tromp AM, Blankenstein MA, Lips P. Effect of mechanical loading on insulin-like growth factor-I gene expression in rat tibia. J Endocrinol. 2007;192(1):131-40.

39. Frost HM. Bone "mass" and the "mechanostat": a proposal. Anat Rec 1987;219(1):1-9.

40. Hughes JM, Petit MA. Biological underpinnings of Frost's mechanostat thresholds: the important role of osteocytes. J Musculoskelet Neuronal Interact. 2010;10(2):128-35.

41. Blanes RJ. To what extent does the crown-implant ratio affect the survival and complications of implant-supported reconstructions? A systematic review. Clin Oral Implants Res. 2009;20(Suppl 4):67-72.

42. Malchiodi L, Cucchi A, Ghensi P, Consonni D, Nocini PF. Influence of crownimplant ratio on implant success rates and crestal bone levels: a 36-month follow-up prospective study. Clin Oral Implants Res. 2014;25(2):240-51.

43. Malchiodi L, Giacomazzi E, Cucchi A, et al. Relationship between crestal bone levels and crown-to-implant ratio of ultra-short implants with a micro-rough surface: a 4-year follow-up prospective study. J Oral Implantol. 2019;(1):18-28.

44. Meijer HJA, Boven C. Is there an effect of crown-to-implant ratio on implant treatment outcomes? A systematic review. 2018;29(Suppl 18):243-52.

45. Gastaldi G, Felice P, Pistilli V, et al. Posterior atrophic jaws rehabilitated with prostheses supported by $5 \times 5 \mathrm{~mm}$ implants with a nanostructured calcium-incorporated titanium surface or by longer implants in augmented bone. 3-year results from a randomised controlled trial. Eur J Oral Implantol. 2018;11(1):49-61.

46. Dias FD, VGA P, Martins CB, Del Fabbro M, Casati MZ. Short implants versus bone augmentation in combination with standard-length implants in posterior atrophic partially edentulous mandibles: systematic review and meta-analysis with the Bayesian approach. Int J Oral Maxillofac Surg. 2019;48(1):90-6.

47. Palacios JAV, Garcia JJ, Carames JMM, Quirynen M, da Silva Marques DN. Short implants versus bone grafting and standard-length implants placement: a systematic review. Clin Oral Investig. 2018;22(1):69-80.

48. Romeo E, Storelli S. Systematic review of the survival rate and the biological, technical, and aesthetic complications of fixed dental prostheses with cantilevers on implants reported in longitudinal studies with a mean of 5 years follow-up. Clin Oral Implants Res. 2012;23(Suppl 6):39-49.

49. Aglietta $M$, Siciliano VI, Zwahlen $M$, et al. A systematic review of the survival and complication rates of implant supported fixed dental prostheses with cantilever extensions after an observation period of at least 5 years. Clin Oral Implants Res. 2009;20(5):441-51.

50. Becker CM. Cantilever fixed prostheses utilizing dental implants: a 10-year retrospective analysis. Quintessence Int. 2004;35(6):437-41.

51. Halg GA, Schmid J, Hammerle CH. Bone level changes at implants supporting crowns or fixed partial dentures with or without cantilevers. Clin Oral Implants Res. 2008;19(10):983-90.
52. Freitas da Silva EV, Dos Santos DM, Sonego MV, et al. Does the presence of a cantilever influence the survival and success of partial implant-supported dental prostheses? Systematic review and meta-analysis. Int J Oral Maxillofac Implants. 2018;33(4):815-23.

53. Storelli S, Del Fabbro M, Scanferla M, Palandrani G, Romeo E. Implantsupported cantilevered fixed dental rehabilitations in fully edentulous patients: systematic review of the literature. Part II. Clin Oral Implants Res. 2018;29(Suppl 18):275-94.

54. Romanos GE, Gupta B, Eckert SE. Distal cantilevers and implant dentistry. Int J Oral Maxillofac Implants. 2012;27(5):1131-6.

55. Kim Y, Oh TJ, Misch CE, Wang HL. Occlusal considerations in implant therapy: clinical guidelines with biomechanical rationale. Clin Oral Implants Res. 2005;16(1):26-35.

56. Asikainen $P$, Klemetti $E$, Vuillemin $T$, et al. Titanium implants and lateral forces. An experimental study with sheep. Clin Oral Implants Res. 1997;8(6):465-8.

57. Duyck J, Ronold HJ, Van Oosterwyck $\mathrm{H}$, et al. The influence of static and dynamic loading on marginal bone reactions around osseointegrated implants: an animal experimental study. Clin Oral Implants Res. 2001;12(3):207-18.

58. Kim P, Ivanovski S, Latcham N, Mattheos N. The impact of cantilevers on biological and technical success outcomes of implant-supported fixed partial dentures. A retrospective cohort study. Clin Oral Implants Res. 2014;25(2):175-84.

59. Vigolo P, Mutinelli S, Zaccaria M, Stellini E. Clinical evaluation of marginal bone level change around multiple adjacent implants restored with splinted and nonsplinted restorations: a 10-year randomized controlled trial. Int J Oral Maxillofac Implants. 2015;30(2):411-8.

60. Naert I, Koutsikakis G, Duyck J, et al. Biologic outcome of implant-supported restorations in the treatment of partial edentulism. Part I: a longitudinal clinical evaluation. Clin Oral Implants Res. 2002;13(4):381-9.

61. Naert I, Koutsikakis G, Quirynen M, et al. Biologic outcome of implantsupported restorations in the treatment of partial edentulism. Part 2: a longitudinal radiographic study. Clin Oral Implants Res. 2002;13(4):390-5.

62. Grossmann Y, Finger IM, Block MS. Indications for splinting implant restorations. J Oral Maxillofac Surg. 2005;63(11):1642-52.

63. Ravida A, Saleh MHA, Muriel MC, Maska B, Wang HL. Biological and technical complications of splinted or nonsplinted dental implants: a decision tree for selection. Implant Dent. 2018;27(1):89-94.

\section{Publisher's Note}

Springer Nature remains neutral with regard to jurisdictional claims in published maps and institutional affiliations.

\section{Submit your manuscript to a SpringerOpen ${ }^{\circ}$ journal and benefit from:}

- Convenient online submission

- Rigorous peer review

- Open access: articles freely available online

- High visibility within the field

- Retaining the copyright to your article

Submit your next manuscript at $>$ springeropen.com 